\title{
Metodologias ativas na extensão universitária: o sujeito como centro e norteador do processo
}

\author{
Juliana Pereira de Araújo1; Maria Paulina de Assis²; Samara C. \\ Machado3; Geiza Constantino ${ }^{4}$.
}

\section{Resumo}

A extensão universitária contemporânea passa por profundas transformações que atuam no sentido de uma reconfiguração que derruba o modelo preponderante alicerçado na transmissão técnica de conhecimento, na exportação de soluções e no verticalismo assistencialista dos processos de ensino-aprendizagem. Neste panorama são retomadas as discussões que permitem ampliar a compreensão da extensão pautando seu desenvolvimento fundamentalmente na concatenação com a realidade local em que se efetua e, nestas discussões, ressurge a preocupação com as metodologias de ensino orientadas para a resolução de problemas das quais sobressaem as chamadas "metodologias ativas". Inspiradas em educadores

1Doutora em Educação. Docente na Universidade Federal de Goiás-Regional Catalão. Membro da Incubadora de Empreendimentos Sociossolidários- INESSOL. Email: juliana.barrado@gmail.com

${ }^{2}$ Doutora em Educação: Currículo pela Pontifícia Universidade de São Paulo, pesquisadora em Design Thinking e Mobile Learning, pesquisadora da Incubadora de Empreendimentos Sociossolidários (INESSOL), professora de Psicologia da Educação da Universidade Federal de Goiás, campus de Catalão. Email: paulina@ufg.br

3 Graduanda do curso de Licenciatura em Pedagogia na Universidade Federal de GoiásRegional Catalão. Membro da Incubadora de empreendimentos SociossolidáriosINESSOL.

${ }^{4}$ Graduanda do curso de Licenciatura em Pedagogia na Universidade Federal de GoiásRegional Catalão. Membro da Incubadora de empreendimentos SociossolidáriosINESSOL. 
como o americano John Dewey e o brasileiro Paulo Freire estas metodologias se destacam ao potencializarem a autonomia e a criticadade dos alunos. A Incubadora de Empreendimentos Sociossolidários (INESSOL) da Universidade Federal de Goiás- Regional Catalão tem construído a extensão universitária buscando aprimorar-se no uso das metodologias ativas entendendo seu papel no apoio e construição de conhecimento e transformação nas cooperativas as quais atua. Neste artigo refletimos como a opção pelas metodologias ativas impacta a trajetória da ação da incubadora em duas cooperativas tornando-a altamente comprometida e interdisciplinar. A tese levantada é que tal escolha deriva em contribuições para a formação de professores alunos e pessoas que ultrapassa a aquisição das condições práticas de ensinar e impacta posturas políticas e ideológicas para as quais o centro do processo formativo é o sujeito e a sua realidade.

Palavras Chave: metodologias ativas; extensão universitária; interdisciplinaridade. 